\title{
Synthesis, Characterization, and Direct Intracellular Imaging of Ultrasmall and Uniform Glutathione-Coated Gold Nanoparticles
}

\author{
Alioscka A. Sousa, * Jeffrey T. Morgan, Patrick H. Brown, April Adams, \\ M. P. Suresh Jayasekara, Guofeng Zhang, Christopher J. Ackerson, \\ Michael J. Kruhlak, and Richard D. Leapman*
}

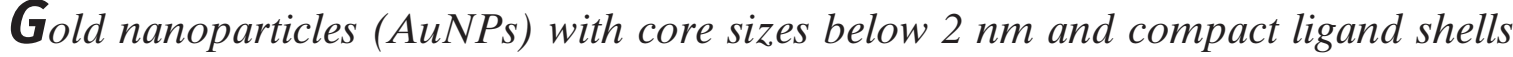
constitute versatile platforms for the development of novel reagents in nanomedicine. Due to their ultrasmall size, these AuNPs are especially attractive in applications requiring delivery to crowded intracellular spaces in the cytosol and nucleus. For eventual use in vivo, ultrasmall AuNPs should ideally be monodisperse, since small variations in size may affect how they interact with cells and how they behave in the body. Here we report the synthesis of ultrasmall, uniform 144-atom AuNPs protected by p-mercaptobenzoic acid followed by ligand exchange with glutathione (GSH). Quantitative scanning transmission electron microscopy (STEM) reveals that the resulting GSH-coated nanoparticles $(\mathrm{Au}(\mathrm{GSH}))$ have a uniform mass distribution with cores that contain 134 gold atoms on average. Particle size dispersity is analyzed by analytical ultracentrifugation, giving a narrow distribution of apparent hydrodynamic diameter of $4.0 \pm 0.6 \mathrm{~nm}$. To evaluate the nanoparticles' intracellular fate, the cell-penetrating peptide TAT is attached noncovalently to $A u(G S H)$, which is confirmed by fluorescence quenching and isothermal titration calorimetry. HeLa cells are then incubated with both $A u(G S H)$ and the $A u(G S H)$-TAT complex, and imaged without silver enhancement of the AuNPs in unstained thin sections by STEM. This imaging approach enables unbiased detection and quantification of individual ultrasmall nanoparticles and aggregates in the cytoplasm and nucleus of the cells.
\end{abstract}

Dr. A. A. Sousa, J. T. Morgan, A. Adams, ${ }^{[+]}$Dr. R. D. Leapman Laboratory of Cellular Imaging and

Macromolecular Biophysics

National Institute of Biomedical Imaging and Bioengineering

National Institutes of Health

Bethesda, MD 20892, USA

E-mail: sousaali@mail.nih.gov; leapmanr@mail.nih.gov

Dr. P. H. Brown, Dr. G. Zhang

Biomedical Engineering and Physical Science Shared Resource National Institute of Biomedical Imaging and Bioengineering National Institutes of Health

Bethesda, MD 20892, USA

[+] Current address: Department of Cellular and Molecular Biology, University of Michigan Medical School, Ann Arbor, MI 48109, USA

DOI: 10.1002/smll.201200071
Dr. M. P. S. Jayasekara

Molecular Recognition Section

Laboratory of Bioorganic Chemistry

National Institute of Diabetes and Digestive and Kidney Diseases

National Institutes of Health

Bethesda, MD 20892, USA

Prof. C. J. Ackerson

Department of Chemistry, Colorado State University

Ft. Collins, CO 80523, USA

Dr. M. J. Kruhlak

Experimental Immunology Branch

National Cancer Institute

National Institutes of Health

Bethesda, MD 20892, USA 


\section{Introduction}

Monolayer-protected gold nanoparticles (AuNPs) constitute a versatile platform onto which small molecules such as drugs and peptides can be attached, and as such they have been intensely investigated for nanomedicine applications in therapy and diagnostics. ${ }^{[1-6]}$ For use in these types of applications, functional AuNPs must be generally capable of entering cells efficiently. ${ }^{[7-9]}$ Previous studies have indicated that the degree of AuNP accumulation inside cells depends on nanoparticle surface charge, nature of the ligand coating, as well as nanoparticle size and shape. ${ }^{[10-15]}$ Usually, AuNPs are internalized by endocytosis, and thus remain confined to endosomes and lysosomes with no general access to the cytosol or nucleus. ${ }^{[7,8]}$ In this scenario, the internalized AuNPs may be unable to produce the desired biological response.

Among the many different classes of AuNPs varying in both size and shape, ultrasmall nanoparticles (here defined to have a gold core of less than $2 \mathrm{~nm}$ in diameter) have been shown to be promising as drug delivery vehicles, intracellular imaging probes, and in vivo imaging contrast agents. ${ }^{[16-20]}$ As drug delivery vehicles, it is expected that ultrasmall AuNPs will show an increased probability of escaping from endosomes and diffusing in the cell cytosol and nucleus without the hindrance of the crowded cellular environment. ${ }^{[17,21]}$ Conversely, larger nanoparticles may have a lower probability of escaping from endosomes, reaching specific intracellular sites, or entering the cell nucleus through the narrow channels of nuclear pore complexes.

Several different protocols inspired by the Brust-Schiffrin method $^{[22]}$ have been employed to synthesize ultrasmall organothiolate protected AuNPs. While it is now recognized that these syntheses can produce magic number ${ }^{[23]}$ molecular formulae that are especially stable, for instance $\mathrm{Au}_{25}(\mathrm{SR})_{18}$, $\mathrm{Au}_{102}(\mathrm{SR})_{44}$ and $\mathrm{Au}_{144}(\mathrm{SR})_{60},{ }^{[24-27]}$ typical syntheses also simultaneously produce kinetically trapped and less stable (and usually less abundant) products with a wide range of molecular formulae. ${ }^{[28]}$ Thus, size uniformity is not always easy to control in these preparations, ${ }^{[29]}$ yet highly uniform or even molecularly pure AuNPs would be ultimately ideal for biomedical and nanomedicine applications. For example, relatively small differences in size can affect the behavior of the AuNPs in the body (e.g., kidney versus liver clearance, degree of extravasation and accumulation in tumors) as well as how they interact with cells (e.g., mode and extent of cellular uptake, intracellular distribution). Size is also an essential variable controlling the physiological properties of other types of nanoparticles, such as quantum dots. ${ }^{[30,31]}$

In this work, we synthesize ultrasmall and uniform AuNPs stabilized by $p$-mercaptobenzoic acid ( $p \mathrm{MBA}$ ) ligands $(\mathrm{Au}(p \mathrm{MBA}))$. This nanoparticle has a presumed chemical formula of $\mathrm{Au}_{144}(p \mathrm{MBA})_{60}$ and a core diameter of $2 \mathrm{~nm}$, and is related to the 102 -atom cluster $\mathrm{Au}_{102}(p \mathrm{MBA})_{44}$ whose crystal structure has been recently determine by X-ray crystallography. ${ }^{[25,26,32]}$ In addition to being ultrasmall and uniform, both the 102- and 144-atom AuNPs can be synthesized in relatively high yields and are amenable to being derivatized for potential applications in biology. ${ }^{[26,33,34]}$ Synthesis of $\mathrm{Au}(p \mathrm{MBA})$ is followed in this work by ligand exchange ${ }^{[35]}$ with the natural tripeptide glutathione (GSH) to make the nanoparticles more biocompatible and stable $(\mathrm{Au}(\mathrm{GSH}))$.

To characterize the size and degree of uniformity of $\mathrm{Au}(p \mathrm{MBA})$ and $\mathrm{Au}(\mathrm{GSH})$ nanoparticles, we use high-angle annular dark-field (HAADF) scanning transmission electron microscopy (STEM) and analytical ultracentrifugation (AUC), two powerful techniques that have been somewhat underutilized in the characterization of ultrasmall nanoparticles for applications in nanomedicine. In the HAADF STEM technique, image contrast scales approximately with the square of the atomic number $Z,{ }^{[36-38]}$ and thus AuNPs $(Z=$ 79) adsorbed onto a thin carbon $(Z=6)$ support film appear with high contrast as bright dots on a dark background. For a nanoparticle of a particular element the integrated pixel intensity is proportional to the mass. Thus, because STEM images can be analyzed quantitatively, ${ }^{[37-41]}$ information on a nanoparticle's mass distribution can be obtained from a histogram of net nanoparticle intensities, which provides for a much more robust metric of particle uniformity than does the particle's diameter. In comparison, the common approach of measuring nanoparticle size from traditional bright-field TEM images can be imprecise and lead to underestimated measurements of size uniformity. When imaged in bright-field TEM, ultrasmall AuNPs give rise to intrinsically low contrast, which falls with decreasing nanoparticle size. Moreover, the limited number of pixels contained within individual AuNPs makes it difficult to define their boundary and thus to determine their diameters accurately. To measure hydrodynamic size distributions of the ultrasmall AuNPs, we use analytical ultracentrifugation, which is a technique that has become increasingly important in the characterization of nanoparticles for biological applications. ${ }^{[31,42-44]}$ One particular advantage of AUC over other methods such as dynamic light scattering is that high-resolution size-distributions can be obtained resulting from hydrodynamic separation of species by centrifugal force. This separation is achieved through differences in sedimentation rates due to heterogeneity in particle size and shape.

Following the synthesis and characterization of the ultrasmall AuNPs, we show next that the TAT cell-penetrating peptide $^{[45]}(\mathrm{CPP})$ can be attached to $\mathrm{Au}(\mathrm{GSH})$ via noncovalent interactions. We then incubate HeLa cells with $\mathrm{Au}(\mathrm{GSH})$ and the $\mathrm{Au}(\mathrm{GSH})$-TAT complex and track the intracellular fate of the nanoparticles using STEM. Images are acquired from samples that have not undergone heavy-metal staining or silver enhancement of the AuNPs, thus providing a route for unbiased detection and quantification of individual ultrasmall nanoparticles and small aggregates inside the cells.

\section{Results and Discussion}

\subsection{Synthesis and Characterization of $A u(p M B A)$}

$\mathrm{Au}(p \mathrm{MBA})$ nanoparticles were first characterized by $\mathrm{UV}$-vis spectroscopy. The UV-vis spectrum displayed in Figure 1A is characteristic of AuNPs having a core diameter of about $2 \mathrm{~nm}$, since there is no surface plasmon absorption peak at 


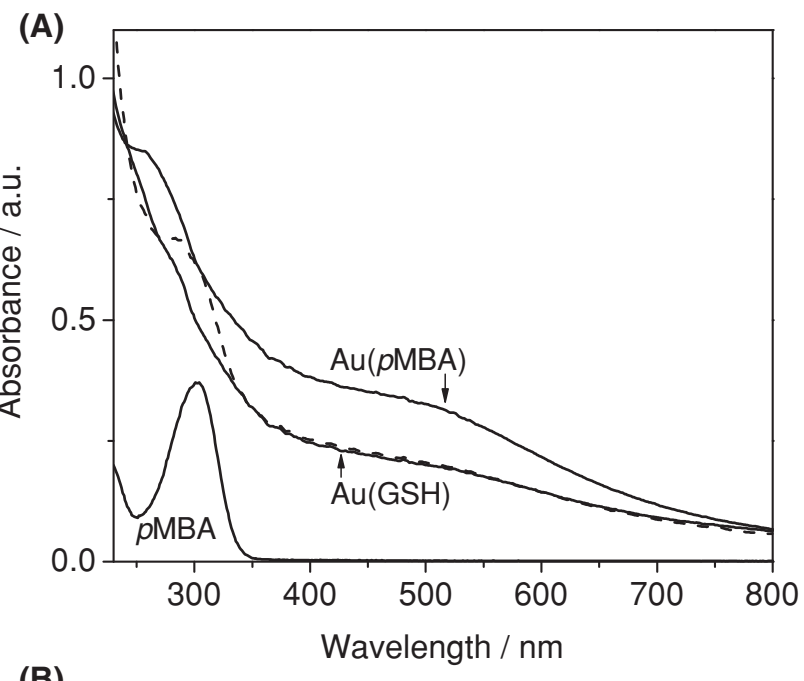

(B)

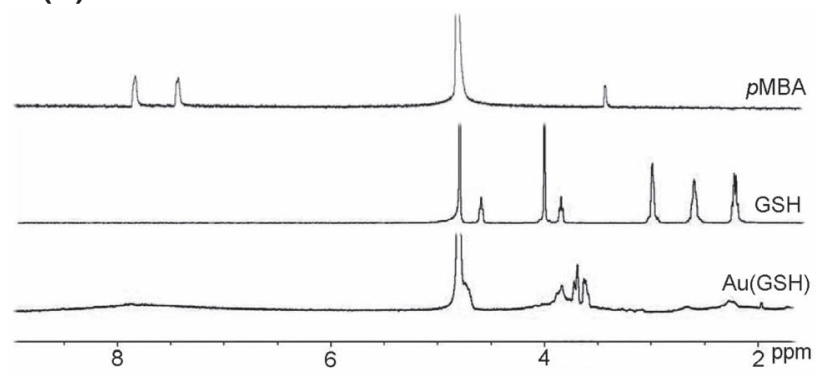

Figure 1. A) UV-vis spectra of $\mathrm{Au}(\mathrm{pMBA}), \mathrm{pMBA}$ ligands, and $\mathrm{Au}(\mathrm{GSH})$ before (dashed line) and after (solid line) purification. B) ${ }^{1} \mathrm{H} N M R$ spectrum of $\mathrm{Au}(\mathrm{GSH})$ shows peaks at chemical shifts in the range from 3.5 to $5 \mathrm{ppm}$, corresponding to GSH ligands attached to the surface of the nanoparticle. This same spectrum does not show any peaks around $8 \mathrm{ppm}$, consistent with complete exchange of pMBA for GSH during ligand exchange. The intense peak at about $4.8 \mathrm{ppm}$ (which has been truncated) is due to $D_{2} O$.

around $500 \mathrm{~nm}$ but only a weak shoulder near this wavelength. ${ }^{[46]}$ The spectrum also shows a peak around $280 \mathrm{~nm}$ originating from the $p \mathrm{MBA}$ ligands.

HAADF STEM imaging confirmed that synthesis of $\mathrm{Au}(p \mathrm{MBA})$ led to a very uniform population of nanoparticles

(A)

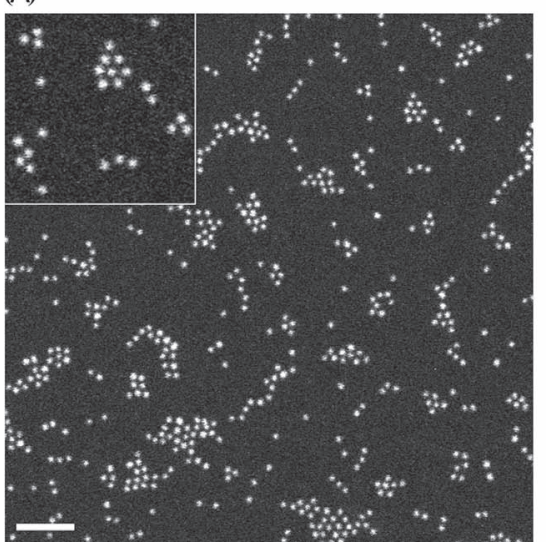

(B)

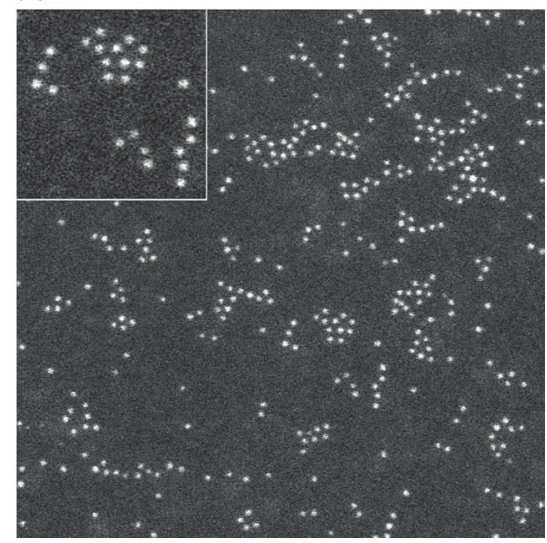

Figure 2. HAADF STEM images for $A) A u(p M B A)$ and $B) A u(G S H)$ AuNPs. The intensity scale is the same in both images. Scale bar, $20 \mathrm{~nm}$. with a core diameter of $2.0 \pm 0.2 \mathrm{~nm}$ (Figure 2A). To better assess quantitatively the uniformity of core sizes, however, we plotted a histogram of integrated intensities for 2000 AuNPs and fitted the histogram to a Gaussian distribution centered at 144 atoms (Figure 3A). We have verified independently the approximate core mass of $\mathrm{Au}(p \mathrm{MBA})$ by comparing intensities with the $\sim 67-\mathrm{Au}$ atom AuNP (Nanogold $®) .{ }^{[47,48]}$ Assuming that $\mathrm{Au}(p \mathrm{MBA})$ nanoparticles have an average diameter of $2.0 \mathrm{~nm}$ and constant density, the full width at half maximum (FWHM) of the histogram translates to an extremely small range of core sizes from 1.9 to $2.1 \mathrm{~nm}$ (Figure 3A). The variation in core mass as given by the FWHM is probably lower since shot noise in the STEM dark-field signal and background estimation of the image intensity both contribute to the measured spread in AuNP intensity.

The ligand shell in addition to the gold core defines the hydrodynamic size of AuNPs in solution. The hydrodynamic diameter of $\mathrm{Au}(p \mathrm{MBA})$ clusters in phosphate buffered solution (PBS) was measured by dynamic light scattering (DLS), yielding an approximate value of $4.5 \pm 0.5 \mathrm{~nm}(n=6$; where $n$ refers to number of measurements). DLS, however, does not have sufficient resolution to yield detailed information on hydrodynamic size dispersity.

Thus, the hydrodynamic size uniformity of the nanoparticles was assessed by AUC. Figure 4A shows the raw sedimentation velocity profiles acquired for $\mathrm{Au}(p \mathrm{MBA})$ particles. The data are well-described by a continuous distribution of non-interacting particles (higher panel), with a root-meansquare difference (rmsd) of 0.00519 absorbance units (lower panel). The resulting sedimentation coefficient distribution exhibits a main peak with a weight-average sedimentation coefficient $s_{\mathrm{w}}$ of $18.7 \mathrm{~S}$ (distribution not shown). Figure 4B shows the apparent-size distribution obtained by conversion of the sedimentation coefficient distribution. Accurate estimation of a hydrodynamic radius requires knowledge of the particle density, and in this experiment we have used a value $\left(4.51 \mathrm{~g} / \mathrm{cm}^{3}\right)$ recently published for particles of a similar size and composition. ${ }^{[49]}$ While this value may lead to errors in the absolute value of the hydrodynamic radius, it would not affect the ability to draw conclusions regarding the overall homogeneity of the distribution of particle sizes. A narrow distribution of apparent particle diameters is observed, namely $D_{\mathrm{h}}=3.6 \pm 0.2 \mathrm{~nm}$ with the error representing the FWHM of the main peak.

\subsection{Ligand Exchange with Glutathione}

Taken together, the above data show that $\mathrm{Au}(p \mathrm{MBA})$ is small and extremely uniform, thus constituting an interesting platform for applications in nanomedicine. However, to ensure the biocompatibility of the nanoparticles, we attempted to substitute the $p$ MBA ligand for GSH through a ligand exchange reaction. It was not clear a priori if most or all $p$ MBA could be substituted for GSH, while maintaining 


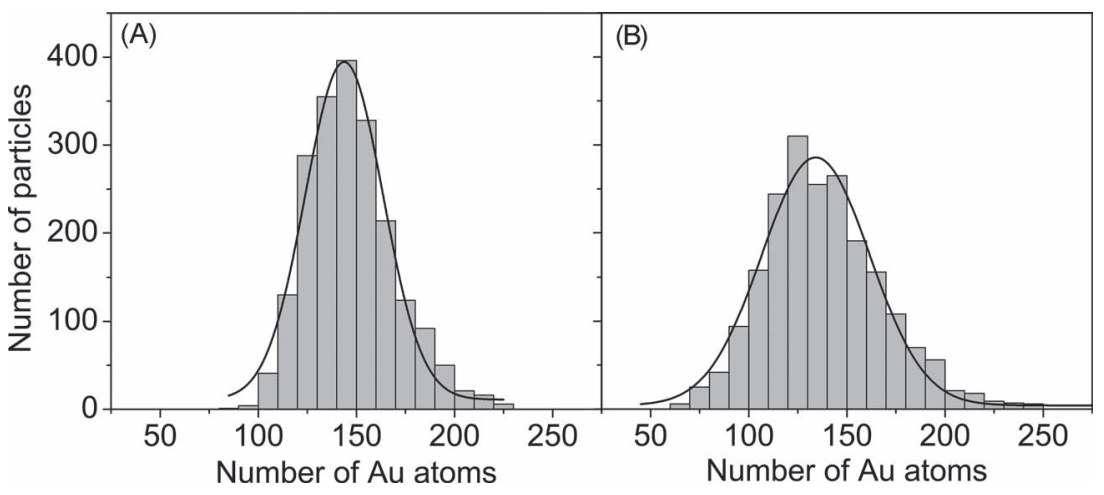

Figure 3. Histograms of integrated intensities represented in terms of number of gold atoms for $A) A u(p M B A)$ and $B) A u(G S H)$ AuNPs. Fitted Gaussian functions are centered at 144 and 134 atoms in (A) and (B), respectively. Size of histogram bin is 10 atoms.
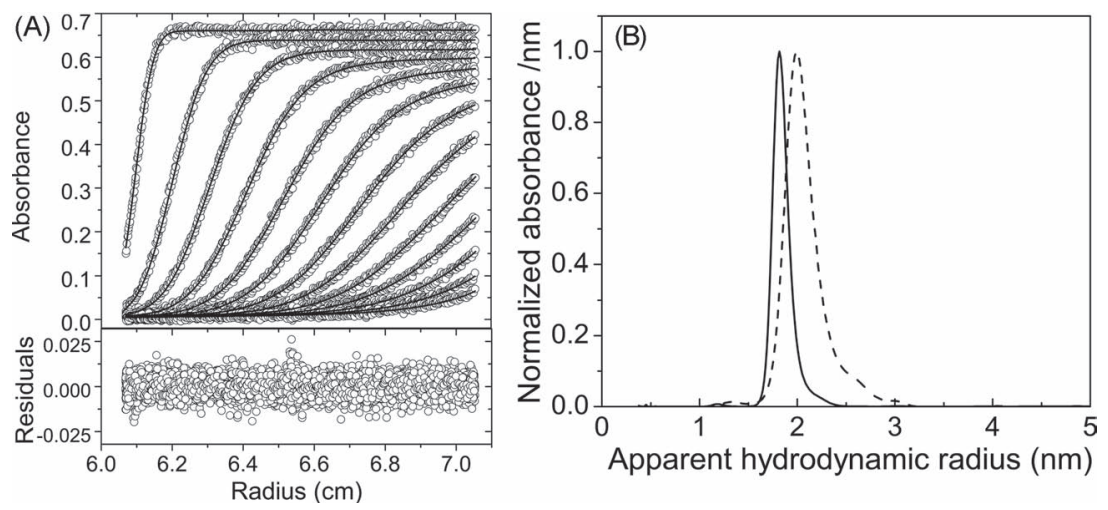

Figure 4. Analytical ultracentrifugation analysis of nanoparticles. A) Sedimentation velocity profiles for $\mathrm{Au}(p M B A)$ (higher panel). The best-fit Lamm equation solutions are shown in overlay (solid lines). The residuals with an rmsd $=0.00519$ OD (lower panel). B) Apparent hydrodynamic radius distribution for $\mathrm{Au}(\mathrm{pMBA})$ (solid trace) and $\mathrm{Au}(\mathrm{GSH})$ (dashed trace) nanoparticles obtained by transformation of the sedimentation coefficient distribution, assuming a particle density of $4.51 \mathrm{~g} / \mathrm{cm}^{3} . D_{\mathrm{h}}=3.6 \pm 0.2 \mathrm{~nm}$ for $\mathrm{Au}(p M B A)$ and $4.0 \pm 0.6 \mathrm{~nm}$ for $\mathrm{Au}(\mathrm{GSH})$.

the original core size and excellent degree of uniformity of $\mathrm{Au}(p \mathrm{MBA})$. In the ligand exchange of up to $\sim 50 \%$ of the ligands on $\mathrm{Au}(p \mathrm{MBA})$, ligand exchange is a straightforward 1:1 stoichiometric reaction, proceeding through an associative mechanism. ${ }^{[50]}$ In more aggressive ligand exchange conditions, oxidative etching of the inorganic core producing $(\mathrm{RS}-\mathrm{Au}-)_{n}$ oligomers can become a competing reaction. ${ }^{[51]}$ While the exact details of the interplay between etching and exchange are unclear, our 10:1 incoming ligand feed ratio and $2 \mathrm{~h}$ time course are consistent with conditions that might give complete ligand exchange accompanied by some AuNP etching.

A UV-vis spectrum obtained after ligand exchange with GSH but before purification shows that the peak due to $p \mathrm{MBA}$ is shifted to $300 \mathrm{~nm}$, which now coincides with the peak position from a solution of free $p \mathrm{MBA}$ molecules (Figure 1A). After washing extensively by centrifuge filtration, the peak at $300 \mathrm{~nm}$ disappears revealing the spectrum of pure $\mathrm{Au}(\mathrm{GSH})$ in solution. Interestingly, the shoulder near $500 \mathrm{~nm}$ for $\mathrm{Au}(\mathrm{GSH})$ is less prominent than that for $\mathrm{Au}(p \mathrm{MBA})$, suggesting that the parent 144-atom gold core might have been slightly etched during ligand exchange. Because a UV-vis spectrum for the analogous 102-atom gold cluster shows a completely smooth decay near $500 \mathrm{~nm},{ }^{[33]}$ it is thus reasonable to assume that the $\mathrm{Au}(\mathrm{GSH}) \mathrm{AuNP}$ contains between 102 and 144 gold atoms.

Although UV-vis demonstrated successful ligand exchange of $p$ MBA for GSH, the sensitivity of the technique is not high enough to establish whether the exchange was complete. We therefore utilized NMR to verify with high accuracy the degree of ligand exchange of $p \mathrm{MBA}$ for GSH (Figure 1B). First, ${ }^{1} \mathrm{H}$ NMR of $\mathrm{Au}(\mathrm{GSH})$ showed peaks at chemical shifts in the range from 3.5 to $5 \mathrm{ppm}$, corresponding to GSH ligands attached on the surface of the nanoparticles. ${ }^{[52]}$ Moreover, the ${ }^{1} \mathrm{H}$ NMR spectrum of $\mathrm{Au}(\mathrm{GSH})$ showed no peaks near $8 \mathrm{ppm}$ that could be attributable to the aromatic protons of $p \mathrm{MBA}$ ligands, indicating therefore that the ligand exchange reaction reached completion.

STEM imaging showed no obvious difference between the $\mathrm{Au}(\mathrm{GSH})$ and $\mathrm{Au}(p \mathrm{MBA})$ nanoparticles (Figure 2). However, a quantitative analysis of the STEM images for $\mathrm{Au}(\mathrm{GSH})$ revealed smaller integrated intensities compared to $\mathrm{Au}(p \mathrm{MBA})$. Two thousand $\mathrm{Au}(\mathrm{GSH})$ nanoparticles were analyzed from a total of 15 images collected over three different days. Using the 144-atom $\mathrm{Au}(p \mathrm{MBA})$ as a calibration standard, the Gaussian function fitted to the $\mathrm{Au}(\mathrm{GSH})$ histogram was then found to be centered at 134 atoms (Figure 3B). The difference between 144 and 134 gold atoms for $\mathrm{Au}(p \mathrm{MBA})$ and $\mathrm{Au}(\mathrm{GSH})$ is relatively small (7\%) but statistically significant $(p<0.001)$. This difference in numbers of atoms is also consistent with the UV-vis results discussed above. The histograms in Figure 3A,B also indicate that the distribution of integrated intensities is slightly broader for $\mathrm{Au}(\mathrm{GSH})$ than for $\mathrm{Au}(p \mathrm{MBA})$. Assuming a constant core density, an analysis of the Gaussian FWHM for $\mathrm{Au}(\mathrm{GSH})$ translates into an estimated range of core sizes of 1.8-2.1 nm.

DLS was utilized to measure the hydrodynamic diameter of $\mathrm{Au}(\mathrm{GSH})$, yielding a value of $4.5 \pm 0.8 \mathrm{~nm}(n=4)$. The apparent hydrodynamic radius distribution determined by AUC is shown in Figure 4B. It was obtained by conversion of the sedimentation coefficient distribution assuming the particles to have the same density as the $\mathrm{Au}(p \mathrm{MBA})$ particles. The weight-average diameter of the distribution is $4.0 \mathrm{~nm}$ with a FWHM of $0.6 \mathrm{~nm}$. It is conceivable that the apparent difference in size between $\mathrm{Au}(p \mathrm{MBA})$ and $\mathrm{Au}(\mathrm{GSH})$ (3.6 versus $4 \mathrm{~nm}$ ) is less pronounced, since the transformation does not take into account any potential differences in particle density. Contributions to this difference may come about by the relative amount of stabilizing ligand attached to the gold surface or from differences in hydration. Figure 4B also shows that 
the width of the distribution is slightly larger for $\mathrm{Au}(\mathrm{GSH})$ compared to $\mathrm{Au}(p \mathrm{MBA})$ ( \pm 0.6 versus $0.2 \mathrm{~nm})$, indicating ligand exchange introduced a small degree of heterogeneity to the resulting $\mathrm{Au}(\mathrm{GSH})$ nanoparticles.

We also measured the Zeta potential of the AuNPs at $\mathrm{pH}$ 7.2 before and after ligand exchange, obtaining $-18.4 \pm 1.1$ and $-15.9 \pm 1.2 \mathrm{mV}$ for $\mathrm{Au}(p \mathrm{MBA})$ and $\mathrm{Au}(\mathrm{GSH})$, respectively.

Overall, the above results indicate that ligand exchange of $\mathrm{Au}(p \mathrm{MBA})$ with GSH can be successfully performed, since the reaction seems to reach completion and the $\mathrm{Au}(\mathrm{GSH})$ product maintains its size relative to the $\mathrm{Au}(p \mathrm{MBA})$ starting material. Although the size uniformity of $\mathrm{Au}(\mathrm{GSH})$ is slightly lower compared to $\mathrm{Au}(p \mathrm{MBA})$ as a result of ligand exchange, $4.0 \pm 0.6 \mathrm{~nm}$ still constitutes a very tight size distribution for potential applications of $\mathrm{Au}(\mathrm{GSH})$ in biology. In future, it will be interesting to test whether $\mathrm{Au}(p \mathrm{MBA})$ can also undergo successful ligand exchange reactions with other suitable molecules (e.g., thiolated oligoethylene glycol) while maintaining the original core size and monodispersity.

\subsection{Electrostatic Binding of TAT to Au(GSH)}

The attachment of CPPs to nanoparticles and other types of cargo can enhance cellular uptake by endocytosis with potential intracellular delivery to the cytosol and nucleus. ${ }^{[21,53-57]}$ Because the $\mathrm{Au}(\mathrm{GSH})$ were negatively charged, we tested whether the polycationic TAT CPP could be attached to the nanoparticles via electrostatic interactions. To measure the degree of association between TAT and $\mathrm{Au}(\mathrm{GSH})$ conveniently through fluorescence, we used a TAT peptide with a carboxyfluorescein fluorescent dye (FAM) attached to its N-terminus. With this setup, a strong fluorescence quenching ${ }^{[58,59]}$ of FAM in the presence of the nanoparticles would indicate close proximity between TAT and $\mathrm{Au}(\mathrm{GSH})$, thus implying association by electrostatic binding.

Figure 5A shows that the fluorescence intensity from a $1 \mu \mathrm{M}$ TAT solution decreased dramatically upon addition of $0.5 \mu \mathrm{M} \mathrm{Au}(\mathrm{GSH})$. Because these are relatively small concentrations, collisional quenching cannot exclusively account for the high degree of quenching $(\sim 90 \%)$ observed in Figure $5 \mathrm{~A}$. Instead, the fluorescence quenching must be due to close binding between TAT and $\mathrm{Au}(\mathrm{GSH})$. Moreover, most of the quenched fluorescence emission could be recovered by adding $\mathrm{NaCl}$ (Figure 5B), adding further evidence that TAT binds to $\mathrm{Au}(\mathrm{GSH})$ electrostatically. For comparison, Figure $5 \mathrm{C}$ reveals that FAM in the presence of $\mathrm{Au}(\mathrm{GSH})$ underwent a much less significant degree of fluorescence quenching. Because FAM and $\mathrm{Au}(\mathrm{GSH})$ are not expected to bind to one another, the small decline in FAM fluorescence as a function of AuNP concentration can be now explained by collisional quenching between FAM and $\mathrm{Au}(\mathrm{GSH}) .{ }^{[60]} \mathrm{To}$ see this more clearly, a characteristic Stern-Volmer (S-V) plot was generated from the data in Figure 5C. As expected, the computed $\mathrm{S}-\mathrm{V}$ plot is linear with an intercept of unity (Figure 5C, inset). The slope of the curve, defined as the $\mathrm{S}-\mathrm{V}$ collisional quenching constant $\left(K_{\mathrm{SV}}\right)$, was found to be $5.5 \times$ $10^{5} \mathrm{M}^{-1}$. This measured $K_{\mathrm{SV}}$ is in good agreement with previously determined $K_{\mathrm{SV}}$ values for the collisional quenching of different fluorophores by a similarly sized gold nanoparticle having $140 \mathrm{Au}$ atoms. ${ }^{[60]}$

The binding between TAT and $\mathrm{Au}(\mathrm{GSH})$ was also confirmed by isothermal titration calorimetry (ITC), which showed decreasing heats of injection as TAT was titrated into a solution of $\mathrm{Au}(\mathrm{GSH})$ (Figure 6A). Integration of the heats and normalization to the molar ratio of TAT to $\mathrm{Au}(\mathrm{GSH})$ in the reaction cell resulted in the binding isotherm displayed in Figure $6 \mathrm{~B}$, which we used to derive a binding stoichiometry of $2.35 \pm 0.02$ TAT molecules per $\mathrm{Au}(\mathrm{GSH})$. We also found that the binding of TAT to $\mathrm{Au}(\mathrm{GSH})$ had a dissociation constant, $K_{\mathrm{d}}$, of $56 \pm 14 \mathrm{~nm}$.

\subsection{Intracellular Imaging of $\mathrm{Au}(\mathrm{GSH})$ Nanoparticles}

Here we investigate the intracellular distribution of $\mathrm{Au}(\mathrm{GSH})$ with and without the presence of TAT bound to the nanoparticle surface. Cell uptake experiments using $\mathrm{Au}(\mathrm{GSH})-\mathrm{TAT}$ were carried out at a solution concentration of $2 \mu \mathrm{M}$ and at a 1:1 molar ratio $\mathrm{Au}(\mathrm{GSH})$ :TAT. These solutions were stable over many days without the formation of visible nanoparticle aggregates. However, we observed that the addition of TAT at higher molar ratios (approximately $>4$ ) could induce aggregation of the AuNPs. Using a Trypan Blue exclusion assay, we also determined that the $\mathrm{Au}(\mathrm{GSH})$ nanoparticles were not acutely cytotoxic in the concentration range of $1-10 \mu \mathrm{M}$.

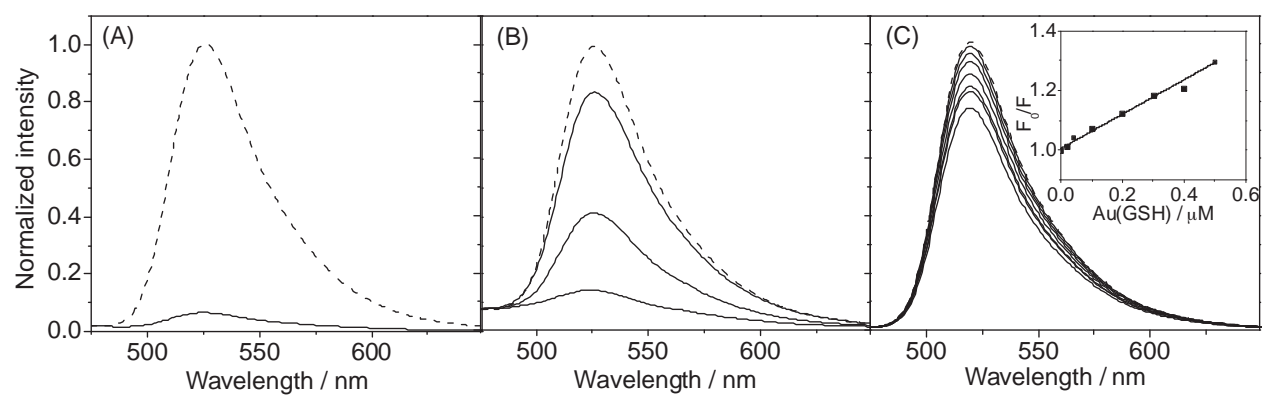

Figure 5. Binding of TAT to $\mathrm{Au}(\mathrm{GSH})$ assessed by fluorescence quenching. A) Fluorescence emission spectra from a $1 \mu \mathrm{m}$ solution of FAM-labeled TAT in the absence (dashed curve) and presence of $0.5 \mu \mathrm{m} \mathrm{Au}(\mathrm{GSH})$. B) Fluorescence spectra from a $1 \mu \mathrm{m}$ solution of Au(GSH)-TAT in the presence of $0,0.25$ and $1 \mathrm{~m} \mathrm{NaCl}$ (from bottom to top). Dashed curve corresponds to a $1 \mu \mathrm{m}$ control solution of FAM-labeled TAT. C) Fluorescence emission spectra from a $1 \mu \mathrm{m}$ solution of FAM in the presence of increasing amounts of $\mathrm{Au}(\mathrm{GSH})$ (from top to bottom: 0.02, 0.04, 0.1, 0.2, 0.3, 0.4, 0.5 $\mu \mathrm{M}$ ). Dashed curve corresponds to a $1 \mu \mathrm{m}$ control solution of FAM. Inset is a Stern-Volmer plot obtained using the fluorescence data in (C). 


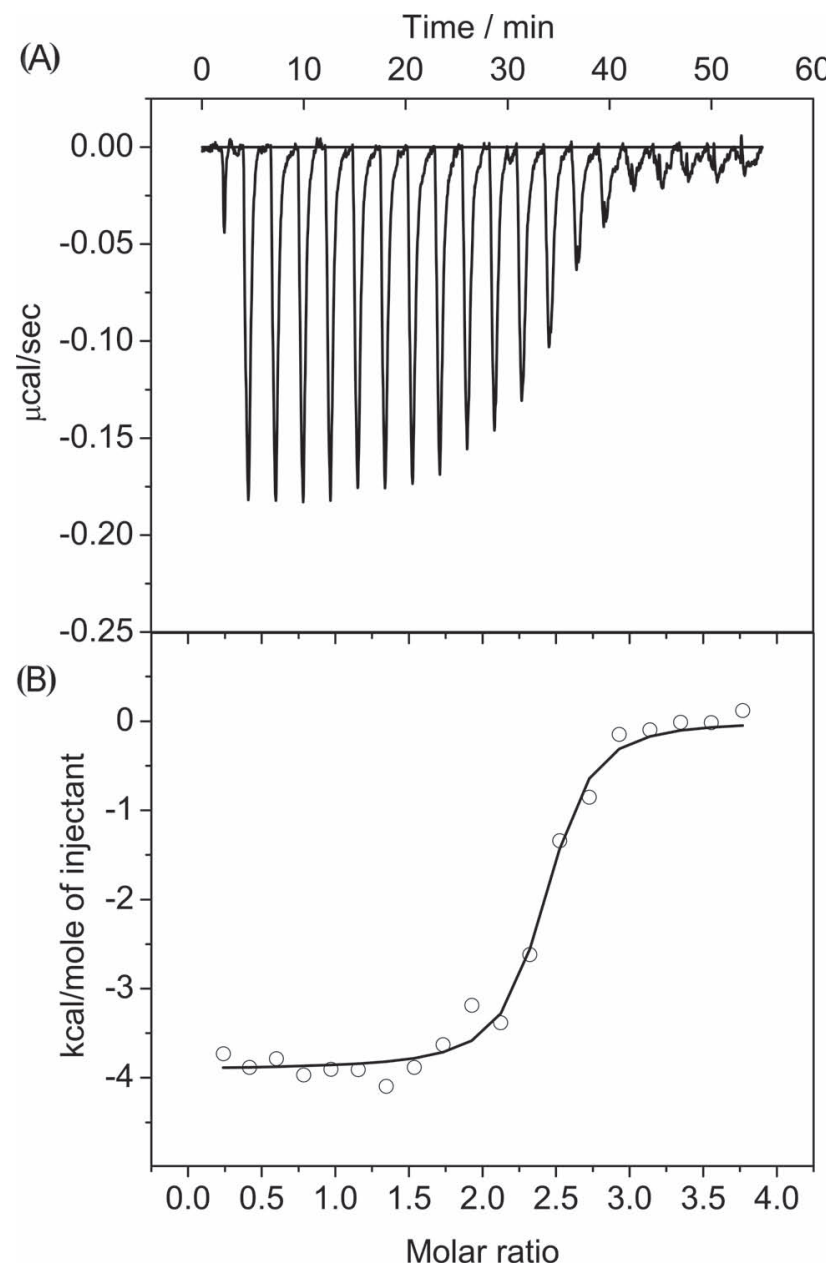

Figure 6. Binding of TAT to $A u(G S H)$ assessed by isothermal titration calorimetry. A) Heat flow with subsequent injections of TAT into a $\mathrm{Au}(\mathrm{GSH})$ solution. B) Binding isotherm obtained by integration of the thermogram. The curve indicates rapid binding of TAT to $A u(G S H)$ with a saturation of binding sites. The data are well described by a single site model, with a TAT to Au(GSH) molar ratio of $2.35 \pm 0.02$ and binding constant of $56 \pm 14 \mathrm{~nm}$.

Cell viability was around $90 \pm 3 \%$ for all concentrations, and the same as that of control experiments where the cells were incubated in PBS only (data not shown).

HeLa cells were incubated with $\mathrm{Au}(\mathrm{GSH})$-TAT for $1 \mathrm{~h}$ and processed for electron microscopy imaging. Importantly, during sample processing, we did not employ osmium tetroxide or any other heavy metal compound. The lack of heavy-metal contrast agents allows ultrasmall $\mathrm{Au}(\mathrm{GSH})$ nanoparticles to be visualized by STEM in thin plasticembedded cell sections without silver enhancement, thus providing a route for entirely unbiased detection of the AuNPs inside the cells. Silver enhancement, on the other hand, can produce false positives by auto-nucleation of silver particles ${ }^{[61]}$ and/or cause coalescence of nearby $\mathrm{Au}(\mathrm{GSH})$ AuNPs into larger particles. The lack of heavymetal contrast agents also rules out the possibility of mistaking ultrasmall nanoparticles to electron dense nanosized artifacts. ${ }^{[39,62-64]}$
Figure 7 shows a few representative STEM images of $\mathrm{Au}(\mathrm{GSH})$ nanoparticles inside HeLa cells. Despite the lack of heavy-metal contrast agents, dark-field STEM images allow a clear delineation of the cytoplasm and nucleus (Figure 7A, left panel). Moreover, the dispersed areas with bright contrast in the nucleus correspond to regions of condensed chromatin, and the large round bright area also in the nucleus corresponds to the nucleolus (Figure 7A). In Figure 7B,C, nanoparticles outside the nucleus appear clustered together and confined to small areas, strongly suggesting that they are inside endosomes (see arrows). In Figure 7B, two larger aggregates (arrowheads) are seen within only $5-10 \mathrm{~nm}$ of the nuclear membrane, strongly suggesting that these particles may be free in the cytosol. In Figure 7A and B, $\mathrm{Au}(\mathrm{GSH})$ nanoparticles are visible inside the nucleus in the form of small aggregates ranging in size from about 4 to $18 \mathrm{~nm}$.

Surprisingly, the intracellular distribution of $\mathrm{Au}(\mathrm{GSH})$ without TAT was remarkably similar to that as described above for $\mathrm{Au}(\mathrm{GSH})$-TAT (data not shown). Importantly, $\mathrm{Au}(\mathrm{GSH})$ nanoparticles could also be observed in the nucleus of HeLa cells. One explanation for this result is that $\mathrm{Au}(\mathrm{GSH})$ has an intrinsic ability to escape from endosomes and access the cytosol and nucleus. Another possibility would involve direct crossing of the plasma membrane by the nanoparticles according to an energy-independent mechanism. In fact, a few recent studies have offered strong evidence that, given the right conditions of capping layer composition and organization, small gold nanoparticles as well as quantum dots are able to cross the plasma membrane of living cells. ${ }^{[11,15,65,66]}$ However, in studies involving nanoparticle localization by electron microscopy, we cannot discount the fact that chemical fixation could potentially lead to the intracellular redistribution of nanoparticles. This issue needs to be investigated further in future studies.

The ability afforded by STEM to visualize ultrasmall AuNPs without silver enhancement in suitable specimens ${ }^{[67-70]}$ is unique in that it enables counting the number of individual $\mathrm{Au}(\mathrm{GSH}) \mathrm{AuNPs}$ contained in larger aggregates in the cytosol and nucleus. We show in Figure 8 nanoparticles of different sizes for which we measured their number of gold atoms using $\mathrm{Au}(\mathrm{GSH})$ as a calibration standard. Some nanoparticles were found to contain 133-174 gold atoms, consistent with single $\mathrm{Au}(\mathrm{GSH}) \mathrm{AuNPs}$, whereas other nanoparticles contained 265-295 atoms, which presumably were aggregates comprising two individual 134-atom Au(GSH) AuNPs. Much larger aggregates were also found with as many as 1500 gold atoms.

It is interesting to consider the primary cellular site where nanoparticle aggregates such as those observed in the nucleus (e.g., see rightmost panels in Figure 7A,B) are formed. First, however, we note that the possibility of $\mathrm{Au}(\mathrm{GSH})$-TAT coalescing into small aggregates prior to being added to the cells can be ruled out by an AUC analysis of Au(GSH)-TAT solutions. Specifically, based on the rotor speed and particle density, it is expected that $\mathrm{Au}(\mathrm{GSH})-\mathrm{TAT}$ particle aggregates as large as $29 \mathrm{~nm}$ would have been detected in solution by AUC if present at concentrations within the linear range of the optical system. By contrast, only a single size distribution curve centered at $D_{\mathrm{h}}=3.8 \pm 0.3 \mathrm{~nm}$ was detected for $\mathrm{Au}(\mathrm{GSH})$-TAT 

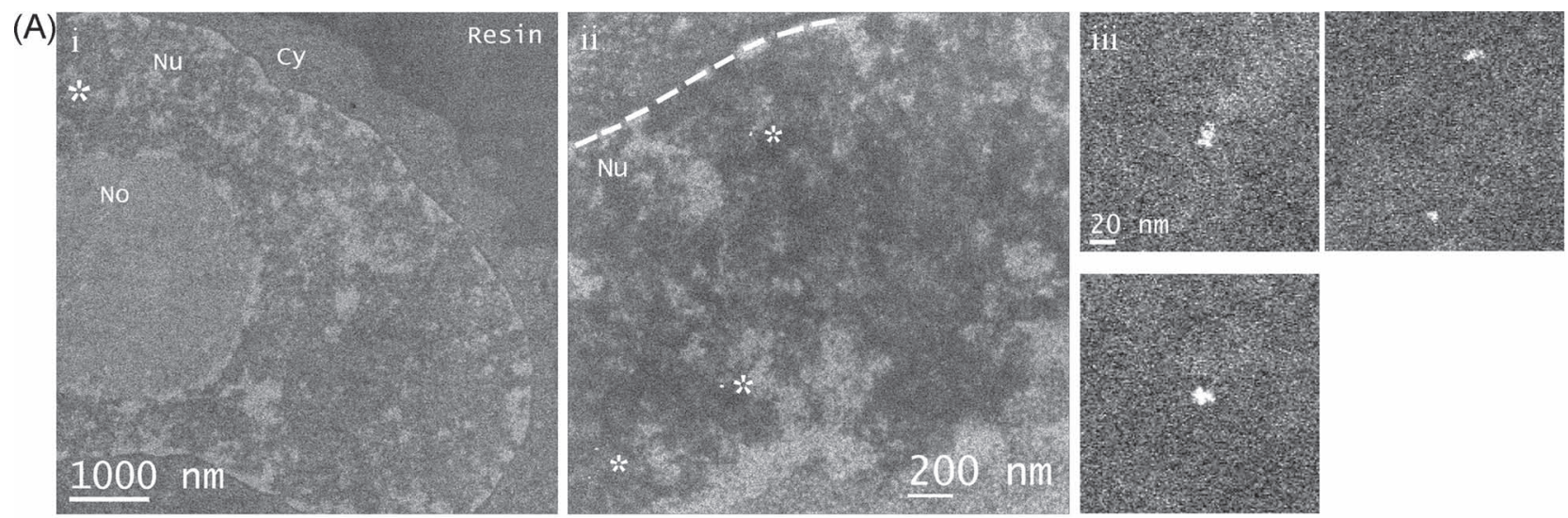

(B)
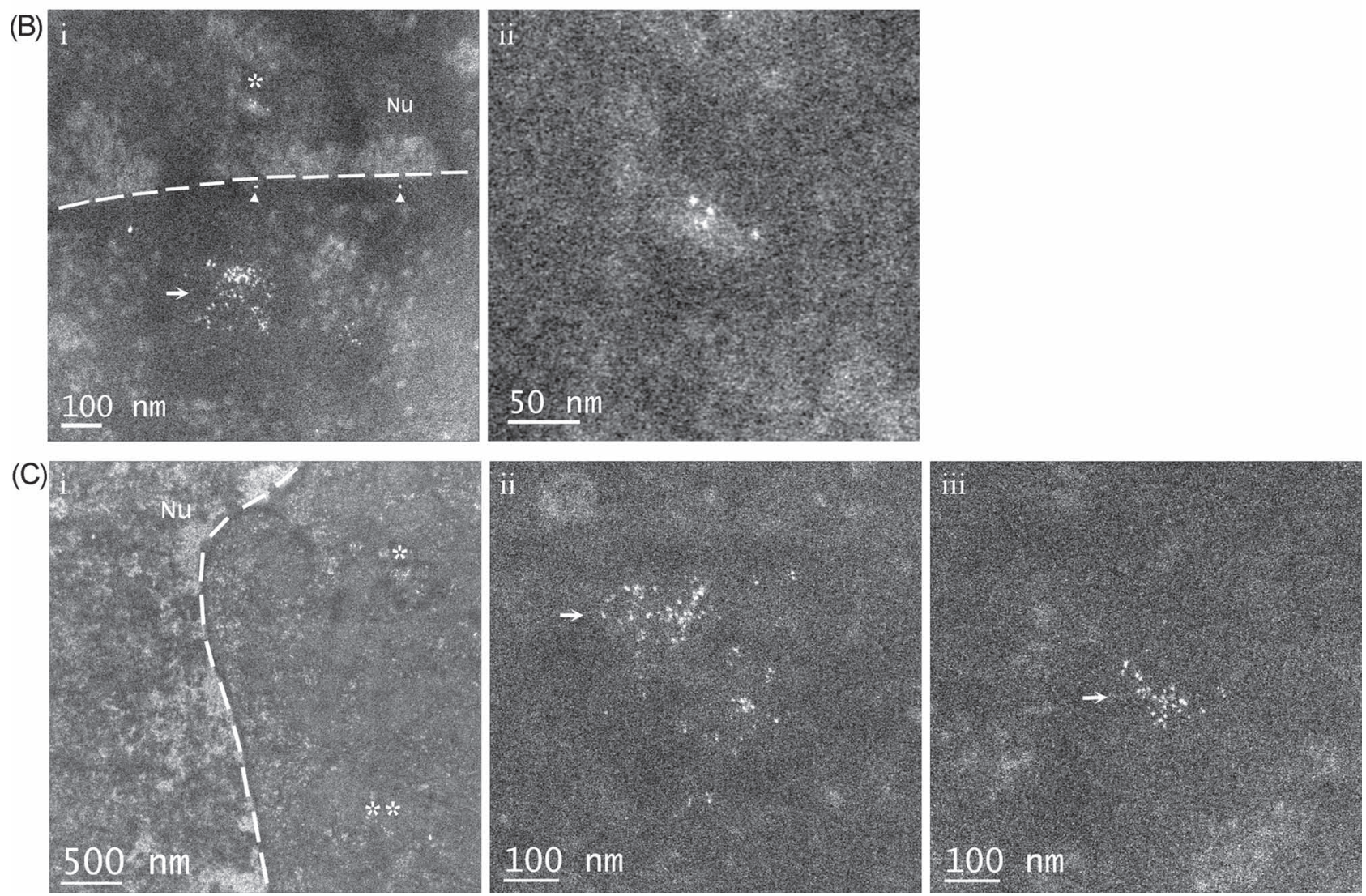

Figure 7. Intracellular imaging of Au(GSH) nanoparticles. A) i) Dark-field STEM imaging allows a clear delineation of the cytoplasm and nucleus in plastic-embedded HeLa cells prepared with no heavy-metal contrast agents. ii) Higher magnification image of the region marked with an asterisk in (i). iii) Expanded views of the regions marked with asterisks in (ii). In (iii), small Au(GSH) nanoparticle aggregates are visible inside the nucleus. B) i) $\mathrm{Au}(\mathrm{GSH})$ nanoparticles both in and outside the nucleus. Nanoparticles outside the nucleus appear mostly clustered together and are likely to be inside endosomes (arrow). Nanoparticles marked with arrowheads appear isolated and are within 5-10 nm of the nuclear membrane, suggesting they are free in the cytosol. ii) Expanded view of the region in the nucleus marked with an asterisk in (i). C) Au(GSH) nanoparticles outside the nucleus. ii,iii) Higher- magnification images of the regions marked with one and two asterisks in (i), respectively. Nu, nucleus; No, nucleolus; Cy, cytoplasm. The dashed lines mark the boundary between the nucleus and cytoplasm.

(data not shown), implying that small $\mathrm{Au}(\mathrm{GSH})$ aggregates must form necessarily in the presence of the cells. Thus, it is possible that $\mathrm{Au}(\mathrm{GSH})$ aggregates observed inside the nucleus were produced by the coalescence of single ultrasmall AuNPs in the cytosol or nucleus after they escaped from endosomes. Alternatively, nanoparticle aggregates might have first formed inside endosomes and then escaped prior to nuclear entry. Still a third possibility would entail the formation of small aggregates at the plasma membrane outside the cell, followed by their uptake via endocytosis and endosomal escape. Differentiating among these possibilities is important, since this would have implications for the role of nanoparticle size in influencing endosomal escape and nuclear entry. We are currently trying to address these and similar questions related to the cellular uptake and intracellular fate of ultrasmall AuNPs. The ability not only to image 

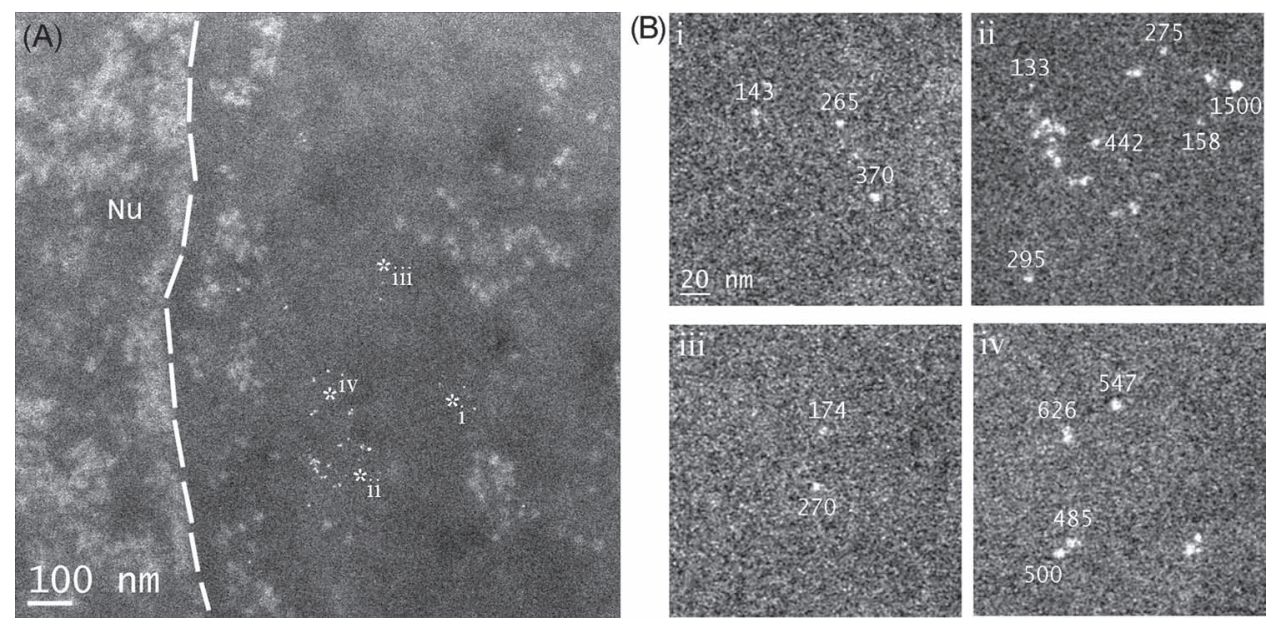

Figure 8. Quantification of Au(GSH) aggregates inside cells. A) Image shows nanoparticles of different sizes for which their number of gold atoms was measured using $\mathrm{Au}(\mathrm{GSH})$ as a calibration standard. The dashed line marks the boundary between the nucleus (Nu) and cytoplasm. B) Expanded views of the regions marked with asterisks in (A). Values annotated in the images indicate the number of gold atoms for the adjacent nanoparticle. Nanoparticles with 133-174 gold atoms correspond to a single Au(GSH) AuNP, whereas those with 265-295 atoms are consistent with two $\mathrm{Au}(\mathrm{GSH})$ AuNPs. Other nanoparticles had higher numbers of gold atoms up to 1500.

ultrasmall AuNPs with high contrast in the STEM but also to analyze the images quantitatively as discussed above should play a significant role in these studies.

\section{Conclusion}

We have synthesized an ultrasmall, 144-atom gold nanoparticle ligand-stabilized with $p \mathrm{MBA}$. These $\mathrm{Au}(p \mathrm{MBA}) \mathrm{AuNPs}$ have a core size of about $2 \mathrm{~nm}$ and are extremely uniform, which are both desirable features in potential biomedical and nanomedicine applications of AuNPs. Specifically, nanoparticles of a sufficiently small size are advantageous for delivery to crowded intracellular spaces in the cytosol and nucleus, and uniformity is essential for achieving consistent biological responses during nanoparticle-cell interactions both in vitro and in vivo.

The synthesis of $\mathrm{Au}(p \mathrm{MBA})$ nanoparticles was followed by a ligand exchange reaction with GSH. We analyzed the resulting $\mathrm{Au}(\mathrm{GSH})$ AuNPs using two powerful techniques that have been somewhat underutilized in the characterization of ultrasmall nanoparticles for applications in nanomedicine. Quantitative STEM imaging revealed that $\mathrm{Au}(\mathrm{GSH})$ was highly uniform and had almost the same number of core gold atoms (134) as the parent 144-atom $\mathrm{Au}(p \mathrm{MBA})$ nanoparticle. Analytical ultracentrifugation showed that $\mathrm{Au}(\mathrm{GSH})$ had a narrow hydrodynamic apparent size distribution of $4.0 \pm$ $0.6 \mathrm{~nm}$. Next, $\mathrm{Au}(\mathrm{GSH})$ as well as $\mathrm{Au}(\mathrm{GSH})$-TAT complexes were incubated with HeLa cells to evaluate the intracellular fate of the nanoparticles. STEM revealed that both $\mathrm{Au}(\mathrm{GSH})$ and $\mathrm{Au}(\mathrm{GSH})$-TAT were effectively internalized by the cells and delivered to the nucleus. A quantitative analysis of the images further indicated that $\mathrm{Au}(\mathrm{GSH})$ were present in the cell interior as single AuNPs as well as in the form of small aggregates containing from 2 to 10 individual nanoparticles.

It will be interesting to explore next whether $\mathrm{Au}(p \mathrm{MBA})$ can be exchanged with other types of ligands to create new monolayer-protected nanoparticles showing exceptional size uniformity for applications in biology. In addition, it will be important to understand more about the intracellular fate of these and other ultrasmall AuNPs, especially the potential role of nanoparticle size and ligand composition in mediating efficient access to the cytosol and nucleus.

\section{Experimental Section}

Synthesis of $A u(p M B A)$ and $A u(G S H)$ Nanoparticles: $\mathrm{Au}(p M B A)$ was synthesized according to a previously published procedure. ${ }^{\text {[2] }}$ Briefly, $\mathrm{HAuCl}_{4}$ (2 mmol) (Sigma-Aldrich) was first dissolved in methanol $(100 \mathrm{~mL})$, and this solution added to an aqueous solution ( $80 \mathrm{~mL}$ ) containing pMBA (TCl America) (6.8 mmol, $\mathrm{pH}>13)$. This step produces a $A u(I)-p M B A$ compound. After stirring for two days, $\mathrm{Au}(\mathrm{I})$-pMBA (50 mL) was added to a water/methanol solution (1 L, 27\%). To this mixture, $\mathrm{NaBH}_{4}$ (Sigma-Aldrich) freshly dissolved in water was added to $\mathrm{Au}$ (I) (1.5 times molar excess). The $\mathrm{Au}(\mathrm{I})-\mathrm{pMBA}-\mathrm{NaBH}_{4}$ mixture was then stirred for $18 \mathrm{~h}$ at room temperature, and the product precipitated by adding methanol (about $1 \mathrm{~L})$ followed by dialysis in water to remove impurities. The dialyzed product was then lyophilized, redispersed in PBS (1×) and kept at $4{ }^{\circ} \mathrm{C}$. We note that the optimum 1.5 -fold molar excess of $\mathrm{NaBH}_{4}$, which yielded the most uniform nanoparticles of the correct size, was found empirically by trying a few different molar excesses in the range from 0.5 to 5 .

Ligand exchange of Au(pMBA) with GSH (Sigma-Aldrich) was carried out by mixing these two components together $(10: 1$ $\mathrm{GSH}:$ MMBA molar ratio) for $2 \mathrm{~h}$ at room temperature. The solution was purified by centrifuge filtration using an Amicon Ultra-4 filter (Millipore) (3 kDa).

UV-Vis Absorbance, Spectrofluorometry, DLS, Zeta Potential: UV-vis spectra and fluorescence emission spectra were recorded using a GENESYS 10S UV-vis spectrophotometer (Thermo Scientific) and F-7000 Fluorescence Spectrophotometer (Hitachi). Dynamic light scattering measurements were carried out in a 
DynaPro NanoStar (Wyatt Technology), and zeta potential performed in a Zetasizer Nano S (Malvern).

STEM Imaging: HAADF STEM images of Au(pMBA) and Au(GSH) were recorded by means of a $300 \mathrm{kV}$ Tecnai TF30 transmission electron microscope (FEI Company) equipped with a Schottky field emission gun and a model-3000 high-angle annular darkfield STEM detector (Fischione Instruments). The nanoparticles were deposited onto ultrathin carbon support films and imaged with a $0.31 \mathrm{~nm}$ pixel size and a probe diameter of approximately $0.5 \mathrm{~nm}$. The microscope was operated with a small camera length of $130 \mathrm{~mm}$ to increase the inner collection semi-angle of the HAADF detector, leading to incoherent imaging conditions suitable for quantitative STEM image analysis of Au(pMBA) and $A u(G S H)$. The large detector inner semi-angle also ensures that the contribution of the low-atomic number pMBA and GSH ligands to the STEM signal is negligible. Thus, integrated image intensities from individual AuNPs are exclusively proportional to their number of core gold atoms.

Analytical Ultracentrifugation: AUC sedimentation velocity experiments were performed using a ProteomeLab XL-I analytical ultracentrifuge (Beckman Coulter) following the protocols outlined in the literature. ${ }^{[71]}$ Briefly, dilute nanoparticle solutions $(400 \mu \mathrm{L})$ prepared in PBS were loaded into double-sector charcoal-filled epon centerpieces with sapphire windows. After a temperature equilibration period, the samples were centrifuged at $25000 \mathrm{rpm}$ at $20^{\circ} \mathrm{C}$. The evolution of the resulting concentration gradient was monitored using the integrated absorbance scanner at a wavelength of $250 \mathrm{~nm}$ with a radial step size of $0.003 \mathrm{~cm}$. The buffer density $(1.00534 \mathrm{~g} / \mathrm{mL})$ and viscosity $(1.0189 \mathrm{cP})$ at $20{ }^{\circ} \mathrm{C}$ were predicted using the software Sednterp (kindly provided by Dr. John Philo). The sedimentation profiles were modeled with numerical solutions to the Lamm equation using the continuous $c(s)$ distribution model, as implemented in SEDFIT (versus 12.5). ${ }^{[72]}$ The sedimentation profiles were analyzed with maximum entropy regularization ${ }^{[72]}$ and algebraic elimination of systematic noise parameters, and refinement by nonlinear regression of the parameters for weight-average frictional ratio $\left(f / f_{0}\right)_{\mathrm{w}}$ and meniscus position. Hydrodynamic radius distributions were obtained by transformation of the sedimentation coefficient distribution using the following relationship: ${ }^{499,73]}$

$r_{i}=\sqrt{\frac{9 \eta s_{i}}{2\left(\rho_{\mathrm{p}}-\rho_{\mathrm{s}}\right)}}$

where $\eta$ represents the solvent viscosity, $\rho_{\mathrm{p}}$ and $\rho_{\mathrm{s}}$ the density of the gold particle and solvent, respectively. Particle density used was assumed to be $4.51 \mathrm{~g} / \mathrm{cm}^{3}$ as determined previously for a similarly stabilized gold nanocluster $\mathrm{Au}_{144}(\mathrm{SR})_{60}\left(\mathrm{R}=-\mathrm{CH}_{2} \mathrm{CH}_{2} \mathrm{PH}\right)$. ${ }^{[49]}$

Isothermal Titration Calorimetry: ITC was used to characterize the interaction between TAT(47-57) (Anaspec) and Au(GSH). ITC was conducted on a Microcal VP-ITC instrument (Northampton, MA) at $20.0^{\circ} \mathrm{C}$. A TAT $(100 \mu \mathrm{m})$ solution prepared in PBS was injected into the calorimeter cell containing $\mathrm{Au}(\mathrm{GSH})(6 \mu \mathrm{m})$ in PBS, using 19 successive injections at $15 \mu \mathrm{L}$ each following an initial injection of $5 \mu \mathrm{L}$. Data analysis was conducted using the manufacturer software. A single site model was used with floating parameters $\left(n, K_{\mathrm{a}}, \Delta H\right)$ optimized by nonlinear regression using the MarquadtLevenburg and Simplex algorithms.

NMR Spectroscopy: ${ }^{1} \mathrm{H}$ NMR spectra were obtained with a Varian Mercury 400 spectrometer using $\mathrm{D}_{2} \mathrm{O}$ as a solvent. The chemical shifts were expressed relative to HOD (4.80 ppm). NMR samples were prepared by dissolving $\mathrm{Au}(\mathrm{GSH})(1.2 \mathrm{mg})$ or pure $p M B A$ or $\mathrm{GSH}$ in $\mathrm{D}_{2} \mathrm{O}(300 \mu \mathrm{L})$ and transferring to Shigemi NMR microtubes.

Cellular Uptake of Au(GSH)-TAT: HeLa cells were seeded into $35 \mathrm{~mm}$ culture dishes and grown in Dulbecco's Modified Eagle Medium supplemented with $10 \%$ fetal bovine serum at $37{ }^{\circ} \mathrm{C}$ and in a $5 \% \mathrm{CO}_{2}$ atmosphere. After $24 \mathrm{~h}$, the cells were washed three times with PBS and incubated for $1 \mathrm{~h}$ with either Au(GSH) or Au(GSH)-TAT (1 mL, $2 \mu \mathrm{m}$ ). Following incubation of the cells with the AuNPs, they were washed five times with PBS and fixed with $2.5 \%$ glutaraldehyde (Electron Microscopy Sciences) for $30 \mathrm{~min}$. After fixation, the cells were dehydrated in a graded series of water/ethanol and embedded in Epon-Aradite resin (Ted Pella). Following polymerization of the resin at $60{ }^{\circ} \mathrm{C}$ for 2 days, 50-nm-thick sections were cut using a Leica EM UC6 Ultramicrotome. No heavy-metal contrast agents were added to the preparation at any time.

In vitro Cytotoxicity: The cytotoxicity of the nanoparticles against HeLa cells was assessed by a Trypan Blue exclusion assay. Cells grown in 6-well plates for $24 \mathrm{~h}$ were treated with different AuNP concentrations ( 0 to $10 \mu \mathrm{m}$ ) for 1 and $5 \mathrm{~h}$, after which they were washed with PBS and incubated back in media. After $24 \mathrm{~h}$, the cells were detached from the well plates with trypsin, centrifuged, and the supernatant discarded. The cells were then resuspended back in PBS and mixed with a 0.4\% Trypan Blue stock solution at a $1: 1(\mathrm{v} / \mathrm{v})$ ratio. After incubation for $2 \mathrm{~min}, 20 \mu \mathrm{L}$ of the solution was loaded into a haemocytometer, and cell viability was calculated as the ratio of cells without blue staining to the total number of cells (approximately $2.3 \times 10^{5}$ cells for each well).

\section{Acknowledgements}

We thank Dr. Kevin Brown and Dr. Vladimir Majerciak for providing cells, M. Mendonca for helping with the cytotoxicity assay, and Dr. X. Chen, Dr. K. Jacobsen, Dr. H. Kalish, Dr. H. Bryant, M. Swierczewska, and Dr. A. Bhirde for providing access to instrumentation. This work was supported by the intramural programs of NIBIB and NCI, NIH. An author name was adjusted on July 23, 2012.

[1] B. Duncan, C. Kim, V. M. Rotello, J. Controlled Release 2010, 148, 122.

[2] S. Rana, A. Bajaj, R. Mout, V. M. Rotello, Adv. Drug Deliv. Rev. 2012, 64, 200.

[3] C. Kim, S. S. Agasti, Z. Zhu, L. Isaacs, V. M. Rotello, Nat. Chem. 2010, 2, 962.

[4] D. A. Giljohann, D. S. Seferos, W. L. Daniel, M. D. Massich, P. C. Patel, C. A. Mirkin, Angew. Chem. Int. Ed. 2010, 49, 3280.

[5] E. Boisselier, D. Astruc, Chem. Soc. Rev. 2009, 38, 1759.

[6] E. C. Dreaden, M. A. Mackey, X. Huang, B. Kangy, M. A. El-Sayed, Chem. Soc. Rev. 2011, 40, 3391.

[7] R. Levy, U. Shaheen, Y. Cesbron, V. See, Nano Rev. 2010, 1, 4889.

[8] L. Y. T. Chou, K. Ming, W. C. W. Chan, Chem. Soc. Rev. 2011, 40, 233.

[9] A. G. Tkachenko, H. Xie, Y. Liu, D. Coleman, J. Ryan, W. R. Glomm, M. K. Shipton, S. Franzen, D. L. Feldheim, Bioconj. Chem. 2004, 15, 482.

[10] E. C. Cho, J. Xie, P. A. Wurm, Y. Xia, Nano Lett. 2009, 9, 1080. 
[11] T. Lund, M. F. Callaghan, P. Williams, M. Turmaine, C. Bachmann, T. Rademacher, I. M. Roitt, R. Bayford, Biomaterials 2011, 32, 9776.

[12] W. Jiang, B. Y. S. Kim, J. T. Rutka, W. C. W. Chan, Nat. Nanotechnol. 2008, 3, 145.

[13] A. Kumari, S. K. Yadav, Expert Opin. Drug Deliv. 2011, 8, 141.

[14] D. B. Chithrani, Mol. Membr. Biol. 2010, 27, 199.

[15] A. Verma, O. Uzun, Y. Hu, Y. Hu, H.-S. Han, N. Watson, S. Chen, D. J. Irvine, F. Stellacci, Nat. Mater. 2008, 7, 588.

[16] C. Zhou, M. Long, Y. Qin, X. Sun, J. Zheng, Angew. Chem. Int. Ed. 2011, 50, 3168.

[17] X. Zhang, H. Chibli, R. Mielke, J. Nadeau, Bioconj. Chem. 2011, 22, 235.

[18] J. F. Hainfeld, D. N. Slatkin, T. M. Focella, H. M. Smilowitz, Br. J. Radiol. 2006, 79, 248.

[19] A. Kumar, H. Ma, X. Zhang, K. Huang, S. Jin, J. Liu, T. Wei, W. Cao, G. Zou, X.-J. Liang, Biomaterials. 2012, 33, 1180.

[20] C. A. Simpson, A. C. Agrawal, A. Balinski, K. M. Harkness, D. E. Cliffel, ACS Nano 2011, 5, 3577.

[21] E. Oh, J. B. Delehanty, K. E. Sapsford, K. Susumu, R. Goswami, J. B. Blanco-Canosa, P. E. Dawson, J. Granek, M. Shoff, Q. Zhang, P. L. Goering, A. Huston, I. L. Medintz, ACS Nano. 2011, 5, 6434.

[22] M. Brust, M. Walker, D. Bethell, D. J. Schiffrin, R. Whyman, J. Chem. Soc., Chem. Commun. 1994, 7, 801.

[23] M. Walter, J. Akola, O. Lopez-Acevedo, P. D. Jadzinsky, G. Calero, C. J. Ackerson, R. L. Whetten, H. Grönbeck, H. Häkkinen, Proc. Natl. Acad. Sci. USA 2008, 105, 9157.

[24] M. W. Heaven, A. Dass, P. S. White, K. M. Holt, R. W. Murray, J. Am. Chem. Soc. 2008, 130, 3754.

[25] P. D. Jadzinsky, G. Calero, C. J. Ackerson, D. A. Bushnell, R. D. Kornberg, Science 2007, 318, 430.

[26] C. J. Ackerson, P. D. Jadzinsky, J. Z. Sexton, D. A. Bushnell, R. D. Kornberg, Bioconj. Chem. 2010, 21, 214.

[27] N. K. Chaki, Y. Negishi, H. Tsunoyama, Y. Shichibu, T. Tsukuda, J. Am. Chem. Soc. 2008, 130, 8608.

[28] Y. Negishi, K. Nobusada, T. Tsukuda, J. Am. Chem. Soc. 2005, 127, 5261.

[29] Y. Li, O. Zaluzhna, Y. J. Tong, Chem. Commun. 2011, 47, 6033.

[30] H. S. Choi, W. Liu, P. Misra, E. Tanaka, J. P. Zimmer, B. I. Ipe, M. G. Bawendi, J. V. Frangioni, Nat. Biotechnol. 2007, 25, 1165.

[31] E. E. Lees, M. J. Gunzburg, T.-L. Nguyen, G. J. Howlett, J. Rothacker, E. C. Nice, A. H. A. Clayton, P. Mulvaney, Nano Lett. 2008, 8, 2883.

[32] C. J. Ackerson, R. D. Powell, J. F. Hainfeld, in Cryo-EM Part A Sample Preparation and Data Collection (Ed: G. Jensen), Academic Press, San Diego CA, 2010, Ch. 9.

[33] Y. Levi-Kalisman, P. D. Jadzinsky, N. Kalisman, H. Tsunoyama, T. Tsukuda, D. A. Bushnell, R. D. Kornberg, J. Am. Chem. Soc. 2011, 133, 2976.

[34] M.-C. Bowman, E. Ballard, C. J. Ackerson, D. L. Feldheim, D. M. Margolis, C. Melander, J. Am. Chem. Soc. 2008, 130, 6896.

[35] M. J. Hostetler, A. C. Templeton, R. W. Murray, Langmuir 1999, 15, 3782.

[36] A. E. Porter, T. P. J. Knowles, K. Muller, S. Meehan, E. McGuire, J. Skepper, M. E. Welland, C. M. Dobson, J. Mol. Biol. 2009, 392, 868.

[37] Z. W. Wang, O. Toikkanen, F. Yin, Z. Y. Li, B. M. Quinn, R. E. Palmer, J. Am. Chem. Soc. 2010, 132, 2854.

[38] N. P. Young, Z. Y. Li, Y. Chen, S. Palomba, M. D. Vece, R. E. Palmer, Phys. Rev. Lett. 2008, 101, 246103.

[39] A. A. Sousa, M. Hohmann-Marriott, M. A. Aronova, G. Zhang, R. D. Leapman, J. Struct. Biol. 2008, 162, 14.

[40] L. D. Menard, S.-P. Gao, H. Xu, R. D. Twesten, A. S. Harper, Y. Song, G. Wang, A. D. Douglas, J. C. Yang, A. I. Frenkel, R. G. Nuzzo, R. W. Murray, J. Phys. Chem. B 2006, 110, 12874.

[41] J. S. Wall, J. Struct. Biol. 1999, 127, 161.
[42] M. Calabretta, J. A. Jamison, J. C. Falkner, Y. Liu, B. D. Yuhas, K. S. Matthews, V. L. Colvin, Nano Lett. 2005, 5, 963.

[43] J. B. Falabella, T. J. Cho, D. C. Ripple, V. A. Hackley, M. J. Tarlov, Langmuir 2010, 26, 12740.

[44] J. M. Zook, V. Rastogi, R. I. MacCuspie, A. M. Keene, J. Fagan, ACS Nano 2011, 5, 8070.

[45] R. Sawant, V. Torchilin, Mol. BioSyst. 2009, 6, 628.

[46] M. J. Hostetler, J. E. Wingate, C.-J. Zhong, J. E. Harris, R. W. Vachet, M. R. Clark, J. David Londono, S. J. Green, J. J. Stokes, G. D. Wignall, G. L. Glish, M. D. Porter, Neal D. Evans, R. W. Murray, Langmuir. 1998, 14, 17.

[47] J. F. Hainfeld, F. R. Furuya, J. Histochem. Cytochem. 1992, 40, 177.

[48] M. Walter, M. Moseler, R. L. Whetten, H. Häkkinen, Chem. Sci. 2011, 2, 1583.

[49] R. P. Carney, J. Y. Kim, H. Qian, R. Jin, H. Mehenni, F. Stellacci, O. M. Bakr, Nat. Commun. 2011, 2.

[50] R. Guo, Y. Song, G. Wang, R. W. Murray, J. Am. Chem. Soc. 2005, $127,2752$.

[51] T. G. Schaaff, R. L. Whetten, J. Phys. Chem. B 1999, 103, 9394.

[52] Z. Wu, R. Jin, ACS Nano 2009, 3, 2036.

[53] Z. Krpetic, S. Saleemi, I. A. Prior, V. See, R. Qureshi, M. Brust, ACS Nano 2011, 5, 5195.

[54] C. C. Berry, Nanomedicine 2008, 3, 357.

[55] J. M. Fuente, C. C. Berry, Bioconj. Chem. 2005, 16, 1176.

[56] J. B. Delehanty, C. E. Bradburne, K. Boeneman, K. Susumu, D. Farrell, B. C. Mei, J. B. Blanco-Canosa, G. Dawson, P. E. Dawson, H. Mattoussi, I. L. Medintz, Integr. Biol. 2010, 2, 265.

[57] P. Nativo, I. A. Prior, M. Brust, ACS Nano 2008, 2, 1639.

[58] M. Swierczewska, S. Lee, X. Chen, Phys. Chem. Chem. Phys. 2011, 13, 9929.

[59] S. Chowdhury, Z. Wu, A. Jaquins-Gerstl, S. Liu, A. Dembska, B. A. Armitage, R. Jin, L. A. Peteanu, J. Phys. Chem. C. 2011, 115, 20105.

[60] P. P. H. Cheng, D. Silvester, G. Wang, G. Kalyuzhny, A. Douglas, R. W. Murray, J. Chem. Phys. B. 2006, 110, 4637.

[61] W. He, C. Kivork, S. Machinani, M. K. Morphew, A. M. Gail, D. B. Tesar, N. E. Tiangco, R. McIntosh, P. J. Bjorkman, J. Struct. Biol. 2007, 107, 103.

[62] C. Brandenberger, M. J. Clift, D. Vanhecke, C. Mühlfeld, V. Stone, P. Gehr, B. Rothen-Rutishauser, Particle and Fibre Toxicology. 2010, 7, 15 .

[63] C. J. Wingard, D. M. Walters, B. L. Cathey, S. C. Hilderbrand, P. Katwa, S. Lin, P. C. Ke, R. Podila, A. Rao, R. M. Lust, J. M. Brown, Nanotoxicology. 2010, 5, 531.

[64] D. B. Peckys, N. d. Jonge, Nano Lett. 2011, 11, 1733.

[65] A. Dubavik, E. Sezgin, V. Lesnyak, N. Gaponik, P. Schwille, A. Eychmuller, ACS Nano DOI: 10.1021/nn204930y.

[66] T. Wang, J. Bai, X. Jiang, G. U. Nienhaus, ACS Nano. 2012, 6, 1251.

[67] N. d. Jonge, N. Poirier-Demers, H. Demers, D. B. Peckys, D. Drouin, Ultramicroscopy. 2010, 110, 1114.

[68] M. A. Aronova, A. A. Sousa, G. Zhang, M. J. Kruhlak, E. Lei, R. D. Leapman, Microsc. Microanal. 2009, 15, 920.

[69] L. Gregori, J. F. Hainfeld, M. N. Simon, D. Goldgaber, J. Biol. Chem. 1997, 272, 58.

[70] J. C. Hernández-Garrido, K. Yoshida, P. L. Gai, E. D. Boyes, C. H. Christensen, P. A. Midgley, Catalysis Today. 2011, 160, 165.

[71] P. H. Brown, A. Balbo, P. Schuck, in Curr. Protoc. Immunol. Unit 18.15. 2008.

[72] P. Schuck, Biophys. J. 2000, 78, 1606.

[73] K. L. Planken, H. Cölfen, Nanoscale. 2010, 2, 1849.

Received: January 11, 2012 Revised: February 8, 2012 Published online: April 20, 2012 